\title{
ALTERASI DAN MINERALISASI BIJIH PADA BATUAN DIORIT DI DAERAH WOMBO, SULAWESI TENGAH
}

\section{ALTERATION AND ORE MINERALIZATION IN DIORITE AT WOMBO AREA, CENTRAL SULAWESI}

\author{
A. Nurul Novia Rahmaningrum ${ }^{1}$, Asrafil, $\mathbf{A}^{2^{*}}$ \\ 1,2Program Studi Teknik Geologi, Fakultas Teknik, Universitas Tadulako; Palu Sulawesi Tengah
}

Received: 2021, M ay $5^{\text {th }}$

A ccepted: 2021, July $12^{\text {th }}$

\section{Keyword: \\ Alteration; \\ Chalcopyrite; \\ Covelite; \\ Ore M ineralization; \\ Pyrite.}

\section{Corespondent Email:}

asrafil@untad.ac.id

\section{H ow to cite this article:}

Rahmaningrum, A.N.N . \& A., A srafil. (2021). Alterasi dan M ineralisasi Bijih Pada Batuan Diorit di Daerah Wombo, Sulawesi Tengah. Jurnal Geofisika Eksplorasi, 7(2), 138-149.

\begin{abstract}
Abstrak. Daerah Wombo Kecamatan Tanantovea Kabupaten Donggala Provinsi Sulawesi Tengah merupakan salah satu daerah yang diduga mempunyai potensi mineralisasi bijih. $\mathrm{Hal}$ ini diindikasikan dengan adanya kenampakan permukaan berupa batuan diorit yang telah mengalami alterasi. Penelitian ini bertujuan untuk mengidentifikasi karakteristik alterasi hidrotermal dan mineralisasi bijih dengan metode penelitian lapangan dan analisis laboratorium berupa petrografi, XRD dan mineragrafi. Berdasarkan analisis petrografi dan XRD, alterasi hidrotermal dicirikan oleh alterasi propilitik (klorit-zeolit-kalsit) dan alterasi argilik (illit-kuarsa-kalsit). Berdasarkan analisis mineragrafi, mineralisasi bijih di daerah penelitian dicirikan oleh kehadiran pirit ( $\left.\mathrm{FeS}_{2}\right)$, kalkopirit $\left(\mathrm{CuFeS}_{2}\right)$ dan kovelit (CuS). Hasil interpretasi menunjukkan bahwa urutan pembentukan mineral bijih berdasarkan pengamatan tekstur yaitu diawali dengan pirit yang hadir mengisi rekahan-rekahan pada batuan, kalkopirit intergrowth dengan pirit yang menandakan kalkopirit hadir bersamaan dengan pirit, replacement kovelit terhadap kalkopirit dan pirit menunjukkan kehadiran kovelit setelah pirit dan kalkopirit.
\end{abstract}

Abstract. Wombo area, Tanantovea District, Donggala Regency, Central Sulawesi Province is one of the areas suspected have ore mineralization indication. It is characterized by the surface appearance of altered diorite rocks. This research aims to identify the characteristics of hydrothermal alteration and ore mineralization by using integrated methods which are field research and laboratory work including petrography, XRD and mineragraphy. Based on petrographic and XRD analysis, the hydrothermal alteration is characterized by propylitic alteration (chlorite-zeolite-calcite) and argillic alteration (illite-quartzcalcite). A ccording to mineragraphy analysis, mineralization in the study area is characterized by the presence of pyrite (FeS2), chalcopyrite (CuF eS2) and covelite (CuS). The interpretation results show that paragenesis of ore mineral based on 
JGE (Jurnal Geofisika Eksplorasi) 07(02) 2021, 138-149

(c) 2021 JGE (Jurnal Geofisika Eksplorasi). This article is an openaccess article distributed under the terms and conditions of the Creative Commons Attribution (CC BY NC) texture observations begins with pyrite filling the fractures in the rock, intergrowth chalcopyrite with pyrite which indicates chalcopyrite is present along with pyrite, replacing covelite against chalcopyrite and pyrite shows the presence of covelite after pyriteand chalcopyrite.

\section{PENDAHULUAN}

Pulau Sulawesi memiliki kondisi geologi yang kompleks, membuat daerah ini kaya akan sumberdaya geologi termasuk mineral logam (Idrus dkk., 2011; Leeuwen \& Pieters, 2012; M aulana dkk., 2020). Pulau ini seakan dirobek oleh berbagi sesar seperti; sesar Palu-Koro, sesar Poso, sesar Matano, sesar W alanopo, sesar Walanae, sesar Gorontalo, sesar batui, sesar Tolo, sesar Makassar dan lain-lain (Bachri \& Sidarto, 2013).

Wombo sebagai daerah studi dalam penelitian ini merupakan salah satu daerah yang dilewati oleh sesar aktif Palu-Koro. Adanya sesar Palu-Koro yang aktif berperan penting dalam pembentukan sesar-sesar minor di sekitarnya yang kemudian menjadi jalur mobilitas fluida hidrotermal menuju ke permukaan dan menjadi tempat terbentuknya mineralisasi (Leeuwen \& Pieters, 2012). Hasil pengukuran orientasi vein baik dipermukaan maupun di bawah permukaan untuk wilayah sekitar sesar Palu-Koro, umunya diperoleh arah vein yang sejajar dengan pola tegangan resional sesar Palu-Koro (Leeuwen \& Pieters, 2012; M arliani, M , dan Asrafil, 2021; W ajdi et al., 2011).

Indikasi mineralisasi di daerah studi ditandai oleh adanya kenampakan alterasi di permukaan pada batuan diorit. Berdasarkan latar belakang kondisi tersebut, dilakukanlah studi terkait karakteristik mineralisasi pada batuan diorit di daerah Wombo. Penelitian ini bertujuan untuk mengidentifikasi karakteritik alterasi hidrotermal dan keterdapatan mineral bijih dalam rangka mengungkap mineralisasi yang terjadi pada batuan diorit di daerah W ombo.

\section{TINJAUAN PUSTAKA}

\subsection{Alterasi Hidrotermal}

Alterasi hidrotermal merupakan proses yang kompleks meliputi perubahan secara mineralogi, kimia dan tekstur yang dihasilkan dari interaksi larutan hidrotermal dengan batuan yang dilaluinya pada kondisi kimiafisika tertentu. Proses alterasi akan menyebabkan terubahnya mineral primer menjadi mineral sekunder yang kemudian disebut dengan mineral yang teralterasi (Pirajno, 2009). Hal yang sangat penting dalam mengenali endapan bijih terutama endapan magmatik dan hidrotermal adalah kehadiran kumpulan mineral tertentu pada batuan yang dilalui oleh larutan hidrotermal sebagai respons akibat adanya reaksi antara larutan hidrotermal dengan batuan samping. Kumpulan mineral tersebut hadir dalam bentuk zona dan antara zona yang satu dengan yang lainnya dibatasi dengan adanya kehadiran mineral-mineral khas (M aulana, 2017).

Klasifikasi tipe alterasi hidrotermal berdasarkan kumpulan mineralnya, menurut Corbett dan Leach (1998) sebagai berikut.

1. Tipe Argilik lanjut

Dicirikan dengan mineral kunci mineral silika, alunit dan kaolinit. Pada temperatur tinggi dikit dan pirofilit terbentuk pada $\mathrm{pH}$ rendah $(\leq 4)$.

2. Tipe Argilik (argilik intermedit)

Dicirikan dengan mineral kunci smektit, montmorillonit, ilit-smektit dan kaolinit. Tipe alterasi jenis ini terbentuk pada temperatur rendah, berikisar 100 hingga $250^{\circ} \mathrm{C}$ dan umumnya mempunyai $\mathrm{pH}$ rendah (sekitar 4-5). 


\section{Tipe Filik}

Alterasi jenis ini ditandai dengan kehadiran mineral serisit atau muskovit, pirofilit, andalusit serisit/muskovit. terbentuk pada temperatur $\left(>200-250^{\circ} \mathrm{C}\right)$. Tipe ini memiliki $\mathrm{pH}$ yang sama dengan tipe argilik.

4. Tipe Propilitik

Alterasi ini ditandai oleh kehadiran mineral epidot dan/atau klorit, albit sekunder dan/atau K-feldspar. Terbentuk pada temperatur relatif rendah $\left(200-300^{\circ} \mathrm{C}\right), \mathrm{pH}$ netral-basa. Dominasi kumpulan mineral alterasi berupa zeolit tergantikan oleh epidot yang dikenal sebagai tipe subpropilitik.

5. Tipe Potasik

Alterasi potasik ditandai dengan kehadiran mineral biotit dan/atau K-feldspar \pm magnetit \pm aktinolit \pm klinopiroksin. Alterasi ini terbentuk pada temperatur yang tinggi, dalam kondisi pH netral-basa.

\subsection{Tekstur Mineral Bijih}

Pengertian tekstur adalah suatu bentuk yang memperlihatkan hubungan antara mineral yang satu terhadap mineral lainnya, hubungan antara mineral inklusi terhadap host mineral, dan hubungan antara mineralmineral terhadap massa dasarnya (M agdalena, 2010).

\subsubsection{Tekstur Pengisian (Open Space Filling)}

Tekstur pengisian umumnya terbentuk pada batuan yang pecah, pada daerah yang umumnya memiliki tekanan yang relatif rendah, sehingga rekahan atau kekar cenderung bertahan (H artusuwarno, 2005).

\subsubsection{Tekstur Penggantian (Replacement)}

Tekstur penggantian adalah tekstur yang menunjukkan penggantian sebagian mineral atau seluruhnya oleh mineral lain tanpa adanya perubahan volume (Ramdohr, 1969).

\subsubsection{Tekstur Tumbuh Bersama (Intergrowth)}

Menurut Ramdohr (1969), tekstur intergrowth terbentuk oleh perubahan temperatur yang tinggi serta dipengaruhi jenis mineral yang menyebabkan terjadinya penyimpangan struktur kristalografi sehingga susunannya tidak beraturan.

\section{METODE PENELITIAN}

Penelitian ini dilaksanakan melalui pendekatan studi lapangan dan analisis laboratorium. Studi lapangan meliputi pengambilan data lapangan yang terdiri dari pengamatan kondisi geologi, alterasi dan pengambilan sampel batuan. Setelah pengumpulan data lapangan selesai, sampel yang telah dipilih kemudian dipreparasi untuk kemudian dianalisis di laboratorium.

Analisis laboratorium meliputi analisis petrografi, mineragrafi dan XRD (X-Ray Diffraction). Analisis laboratorium yang dilaksanakan, diuraikan sebagai berikut.

\subsection{Analisis Petrografi}

Analisis petrografi menggunakan mikroskop polarisasi. Analisis ini bertujuan untuk mengidentifikasi tekstur, mineral penyusun batuan, dan indikasi kehadiran mineral alterasi serta penamaan batuan pada daerah penelitian. Analisis ini dilakukan pada tiga sampel batuan di lokasi penelitian.

\subsection{Analisis Mineragrafi}

Analisis mineragrafi menggunakan mikroskop bijih dilakukan terhadap empat sampel batuan yang dipreparasi dalam bentuk sayatan poles. Analisis ini bertujuan untuk menentukan jenis mineral bijih, deskripsi tekstur yang nantinya dapat membantu untuk interpretasi paragenesanya.

\subsection{AnalisisXRD (X-Ray Diffraction)}

Analisis kimia batuan menggunakan XRD (X-Ray Diffraction) bertujuan untuk mengetahui kandungan mineral yang tidak dapat dideterminasi secara megaskopis dan mikroskopis. A nalisis XRD dilakukan terhadap tiga sampel batuan teralterasi dari lokasi studi untuk mengidentifikasi kehadiran mineral 
alterasi yang menjadi kunci dalam penentuan tipe alterasi.

\section{HASIL DAN PEMBAHASAN}

\subsection{Alterasi Hidrotermal}

Mineral alterasi hidrotermal di daerah penelitian yang diperoleh dari analisis XRD pada tiga sampel batuan repserentatif yang menunjukkan kehadiran mineral-mineral ubahan (teralterasi) (Tabel 1).

Tabel 1. Hasil Analisis XRD Sampel Batuan Teralterasi

\begin{tabular}{ccc}
\hline Sampel & Mineral & Tipe \\
\hline NW B 1B & $\begin{array}{c}\text { Kuarsa, M uskovit, } \\
\text { Klorit, Sodalit, }\end{array}$ & Propilitik \\
NW B 7 & $\begin{array}{c}\text { Rutil, Lepidolit } \\
\text { Kalsit, }\end{array}$ & Propilitik \\
NW B 3 & Klinoklorit, & Argilik \\
& Kuarsa, & \\
& Leumontit (grup & \\
& Zeolit), Albit & \\
& Kuarsa, Illit, & \\
& Kalsit, Magnetite, & \\
& Montmorilonit &
\end{tabular}

Alterasi hidrotermal yang tersingkap pada daerah penelitian seluas $32 \%$ dari luas keseluruhan daerah penelitian, sedangkan $68 \%$ dari luas keseluruhan daerah penelitian merupakan daerah yang tidak mengalami alterasi (Gambar 1). Kumpulan mineral hasil analisis XRD menunjukkan bahwa alterasi hidrotermal pada daerah penelitian dapat dikelompokkan menjadi dua tipe alterasi hidrotermal (Gambar 2) dengan mengacu pada klasifikasi Corbett dan Leach (1998), yaitu:

1. Alterasi Propilitik (klorit-zeolit-kalsit)

2. Alterasi Argilik (ilit-kuarsa-kalsit)

\subsubsection{Alterasi Propilitik}

Tipe alterasi ini hadir paling luas pada batuan yang ada yakni sekitar 31\% dari luas keseluruhan daerah penelitian. Alterasi propilitik terbentuk oleh campuran dan evolusi fluida pada sistem hidrotermal antara fluida juvenil dan meteorik (Ruppel dkk., 2018). Pada singkapan di lapangan, tipe alterasi ini dicirikan dengan warna batuan abuabu kehijauan dan berwarna kecoklatan pada kondisi lapuk.



Gambar 1. Peta Zonasi Alterasi Hidrotermal 
W arna hijau tersebut disebabkan kehadiran mineral ubahan klorit (Gambar 3). Mineral ubahan lain yang hadir adalah zeolit, karbonat, kuarsa, adularia, al bit dan mineral lempung.

Berdasarkan pengamatan petrografi, klorit hadir berserabut dan sebagai agregat halus, berukuran 0.5-2.5 mm. Klorit merupakan ubahan mineral yang mengandung $\mathrm{Mg} / \mathrm{Fe}$ seperti plagioklas dan biotit, hal ini ditunjukkan oleh bentuk awal dari mineral plagioklas (Gambar 4a) dan mineral biotit
(Gambar 4c) terlihat jelas mineral plagioklas dan biotit tersebut telah mengalami alterasi menjadi klorit. Mineral klorit ini terbentuk karena reaksi antara mineral plagioklas maupun biotit dengan larutan hidrotermal. Kalsit hadir sebagai urat. Kalsit merupakan mineral alterasi dari mineral yang mengandung unsur $\mathrm{Ca}$. Adapun mineral lempung merupakan hasil alterasi dari dari mineral-mineral feldspar.

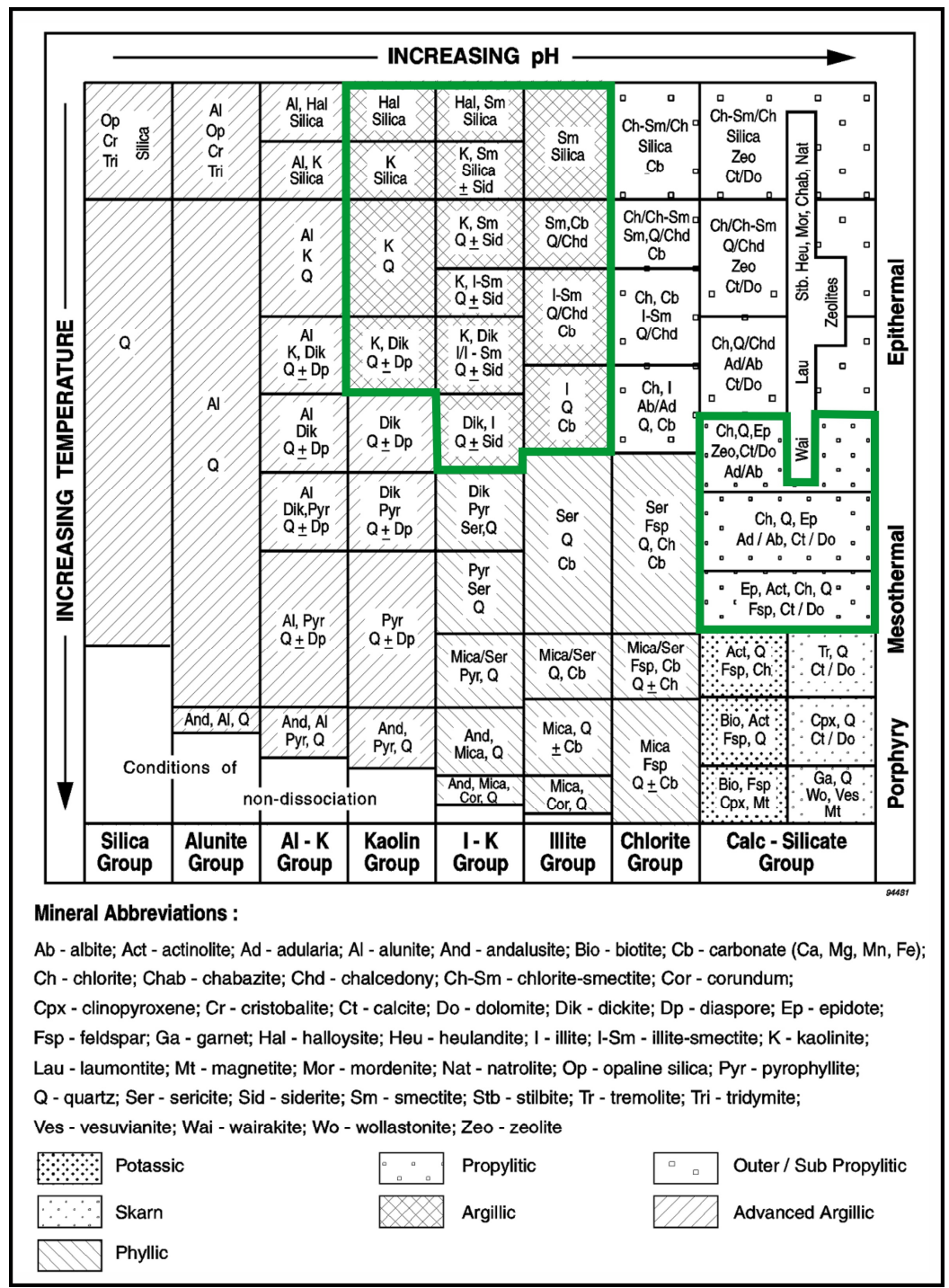

Gambar 2. Himpunan mineral ubahan pada sistem hidrotermal (Corbett $\&$ Leach, 1998). Tipe alterasi argilik dan propilitik yang dijumpai pada daerah penellitian (garis hijau). 


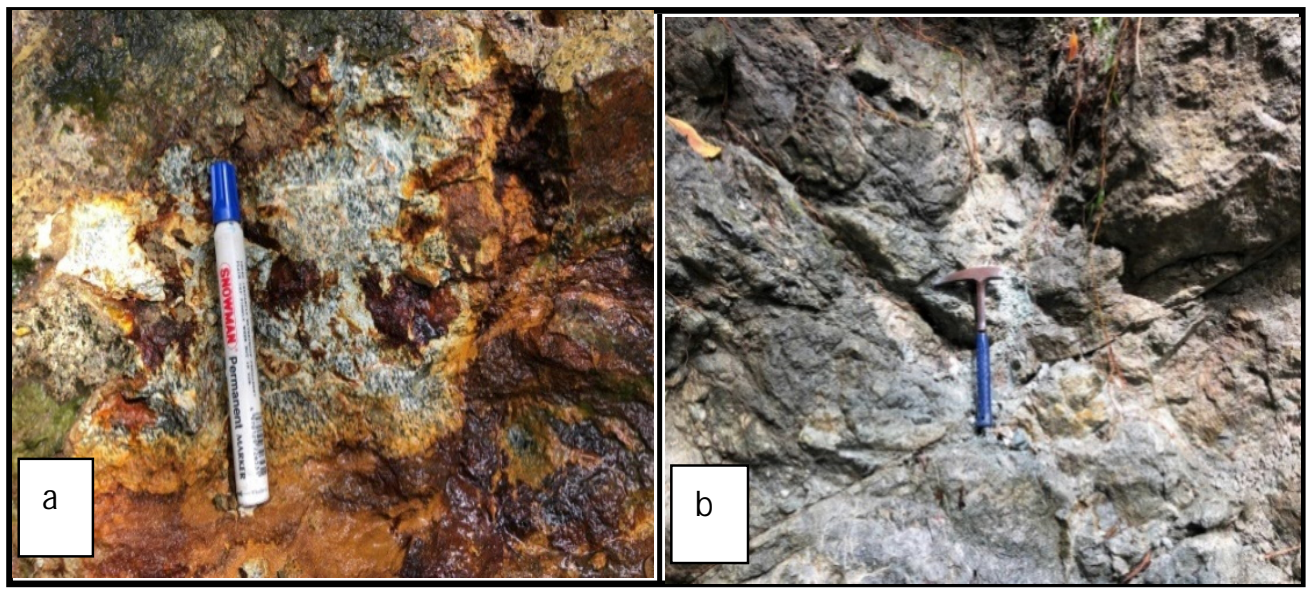

Gambar 3. Kenampakan singkapan batuan yang mengalami alterasi propilitik pada stasiun 01 (a) dan stasiun 07 (b).

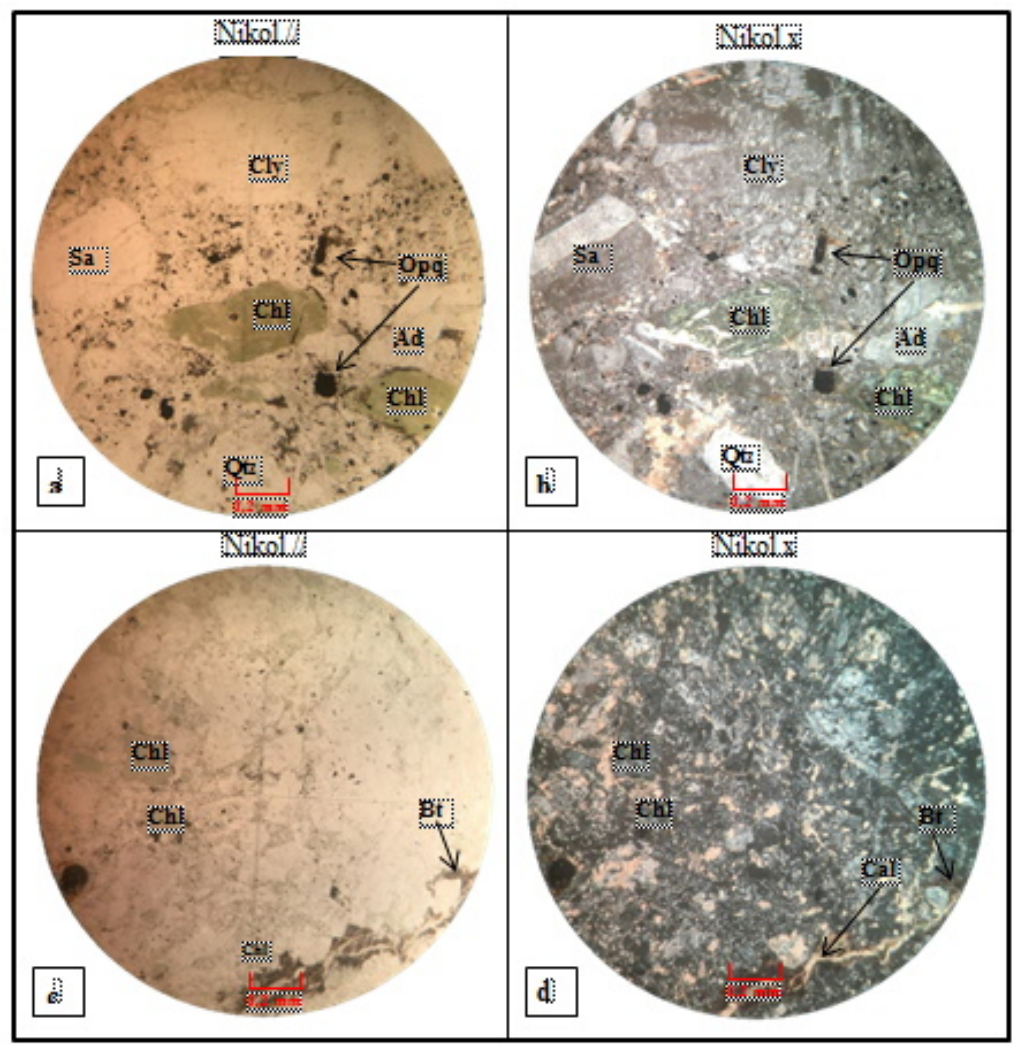

Gambar 4. Sayatan petrografi sampel batuan NWB 1C dari stasiun 01. Pada kenampakan nikol sejajar (a) dan nikol silang (b) yang tersusun atas mineral klorit (Chl), kuarsa (Qtz), adularia (Ad), sanidin (Sa), mineral lempung (Cly) dan mineral opak (Opq). Sayatan petrografi sampel batuan pada stasiun 08. Kenampakan nikol sejajar (c) dan nikol silang (d) yang tersusun atas mineral klorit (Chl), biotit (Bt) dan urat kalsit (Cal).

Dari hasil analisis XRD (X-ray Diffraction), dijumpai mineral klorit (Gambar 5), mineral albit, mineral laumontit yang termasuk dalam grup zeolit (Gambar 6). Mineral laumontit 
terbentuk pada $\mathrm{pH}$ netral dengan temperatur berkisar $150-200^{\circ} \mathrm{C}$ (Corbett \& Leach, 1998). Kestabilan temperatur dan tekanan yang dimiliki zeolit membuat mineral ini memiliki peranan yang sangat penting pada endapan epitermal (Pirajno, 2009).

Berdasarkan kumpulan mineral alterasi yang didominasi oleh mineral klorit, zeolit, kalsit, adularia dan mineral lempung maka kumpulan mineral alerasi ini dapat dimasukkan dalam jenis alterasi propilitik sesuai dengan klasifikasi dari Corbett dan Leach (1998). Berdasarkan kehadiran kumpulan mineral alterasi menurut $\mathrm{pH}$ fluida hidrotermal menunjukkan indikasi alterasi fluida yang mendekati $\mathrm{pH} \mathrm{N}$ ormal pada suhu relatif 200 hingga $300^{\circ} \mathrm{C}$ (Corbett \& Leach,
1998; Pirajno, 2009; W hite \& H edenquist, 1995; Winter, 2014). Hal yang sama ditemukan di area sebelah selatan lokasi studi (Poboya), dimana kumpulan mineral pada alterasi propilitik dalam sebagai produk dari interaksi batuan dan fluida hidrotermal yang hampir netral dan asam (Syafrizal dkk., 2017).

Beberapa bagian alterasi propilitik kemungkinan juga telah terbentuk sebelum pengendapan bijih dan mungkin secara genetik tidak berhubungan dengan proses hidrotermal pembentuk bijih (Evans, 2009). $\mathrm{Hal}$ ini menjadi alasan mengapa pada zona alterasi propilitik yang ditemui umumnya mempertahankan beberapa tekstur utama dari batuan induk (Zar dkk., 2018).

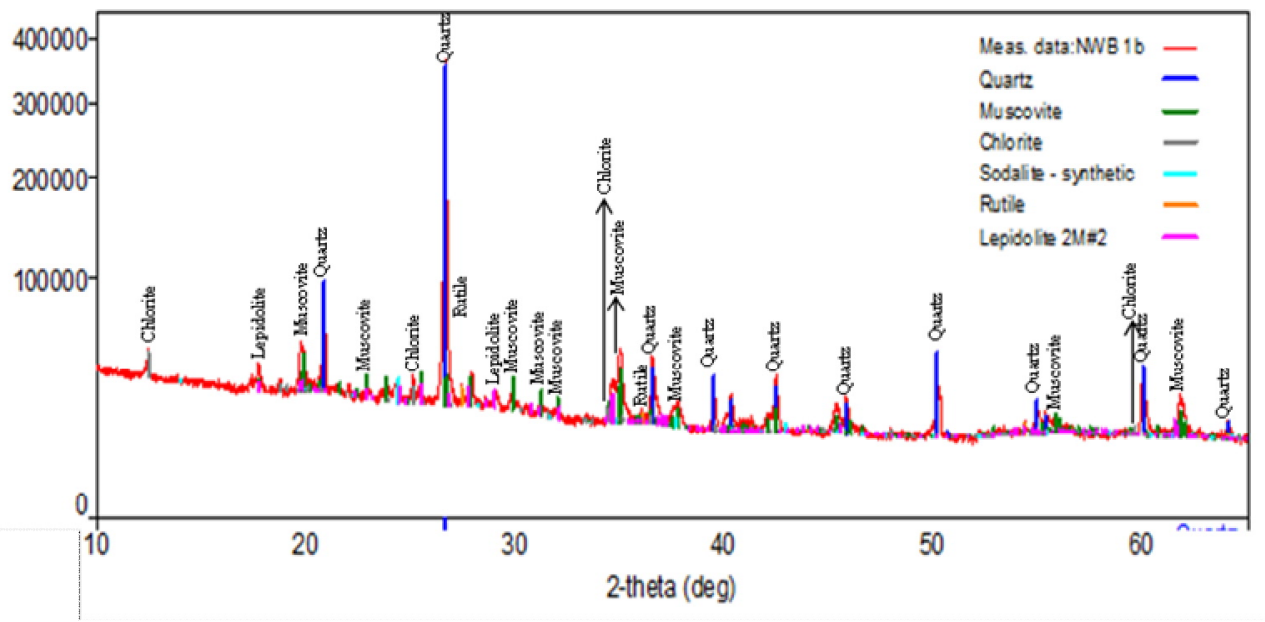

Gambar 5. Grafik hasil analisis XRD sampel NWB 1B.

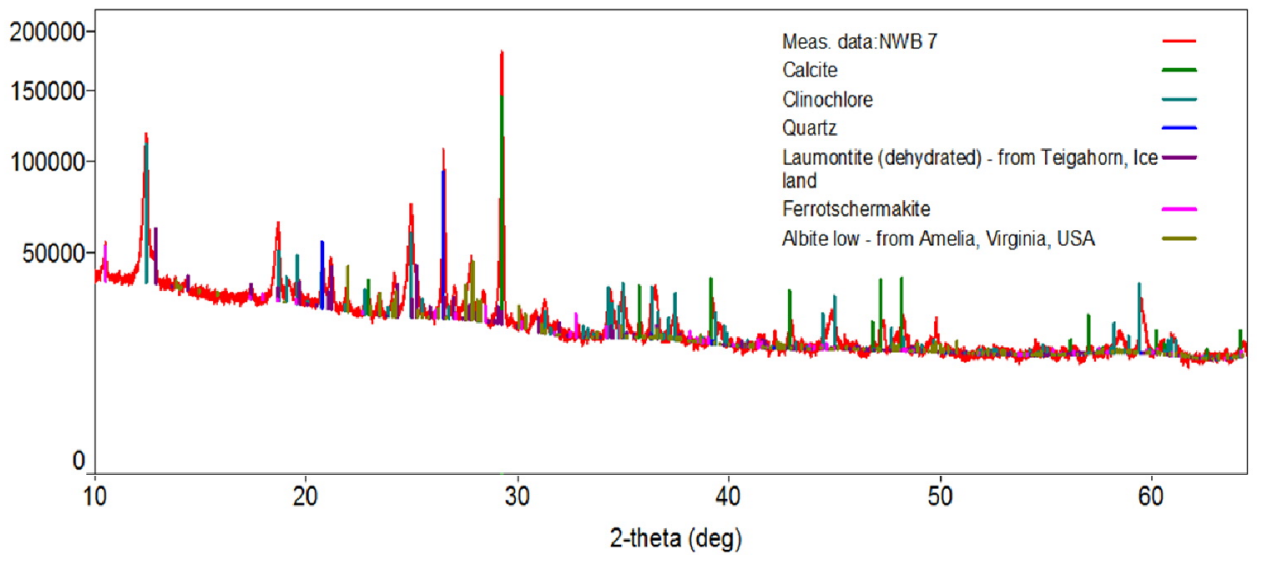

Gambar 6. Grafik hasil analisis XRD sampel NWB 7. 


\subsubsection{Alterasi Argilik}

Alterasi argilik dijumpai tersingkap di daerah penelitian dengan luasan yang sangat kecil, hanya sekitar 1\% dari luas keseluruhan daerah penelitian. Singkapan di lapangan menunjukan kenampakan dengan warna batuan abu-abu keputih-putihan dan cenderung lunak (Gambar 7). M ineral alterasi yang dapat diidentifikasi secara petrografi adalah mineral lempung, kuarsa dan karbonat. Sedangkan untuk jenis mineral lempung yang muncul berdasarkan analisis XRD (X-ray Diffraction) adalah ilit dan montmorilonit (Gambar 8).

Berdasarkan pengamatan petrografi (Gambar 9), tekstur dari batuan asal sudah tidak dapat dilihat lagi pada zona ini dan mineral-mineral primer juga sudah sepenuhnya tergantikan oleh kuarsa dan mineral lempung. Mineral lempung hadir sebagai hasil ubahan dari massa dasar, kuarsa hadir mengisi rongga-rongga batuan yang menggantikan fenokris dan massa dasar. Kuarsa terbentuk dari penurunan temperatur larutan hidrotermal yang cepat. Kalsit hadir sebagai urat, terbentuk dari proses pendidihan fluida yang memiliki unsur $\mathrm{CO}_{2}$ yang cukup tinggi (Corbett \& Leach, 1998). Berdasarkan dominasi kumpulan mineral alterasi oleh mineral lempung, kuarsa dan karbonat maka dikelompokkan ke dalam jenis alterasi argilik sesuai dengan klasifikasi dari Corbett dan Leach (1998). Alterasi argilik ini terbentuk pada suhu rendah berkisar 100 hingga $250^{\circ} \mathrm{C}$ dan secara umum mempunyai $\mathrm{pH}$ rendah (sekitar 4-5) (Corbett \& Leach, 1998).

\subsection{Mineralisasi Bijih}

Pengamatan mineral bijih dilakukan terhadap empat sampel batuan yang diduga sebagai batuan pembawa mineral bijih dengan analisis mikroskopis bijih (mineragrafi). U mumnya mineralisasi bijih yang dijumpai di daerah penelitian merupakan mineral-mineral sulfida, antara lain: pirit $\left(\mathrm{FeS}_{2}\right)$, kalkopirit ( $\mathrm{CuFeS}_{2}$ ) dan kovelit (CuS).

Mineralisasi yang terdapat di daerah penelitian dijumpai dalam bentuk menyebar (disseminated) pada batuan dan urat kuarsakalsit. U rat kuarsa dan kalsit hadir dengan tekstur berlapis (crustiform banding) (Gambar 10). Tekstur mineral bijih yang diperoleh dari daerah penelitian terdiri dari tekstur pengisian (open space filling), tekstur intergrowth dan tekstur penggantian (replacement).

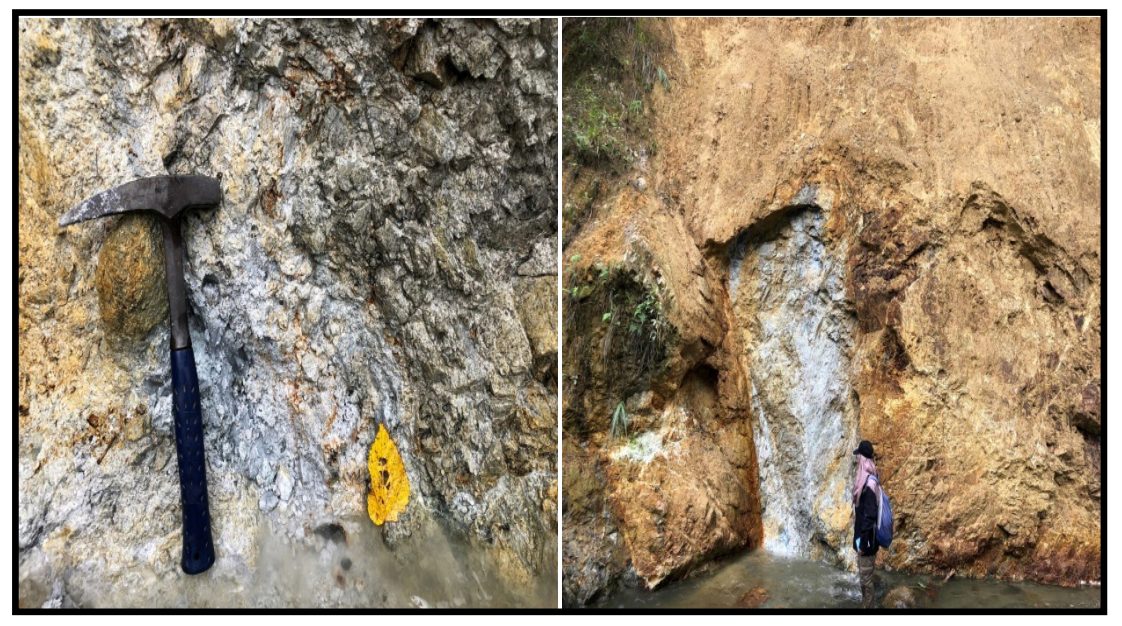

Gambar 7. Kenampakan singkapan batuan yang mengalami alterasi argilik pada stasiun 03. 


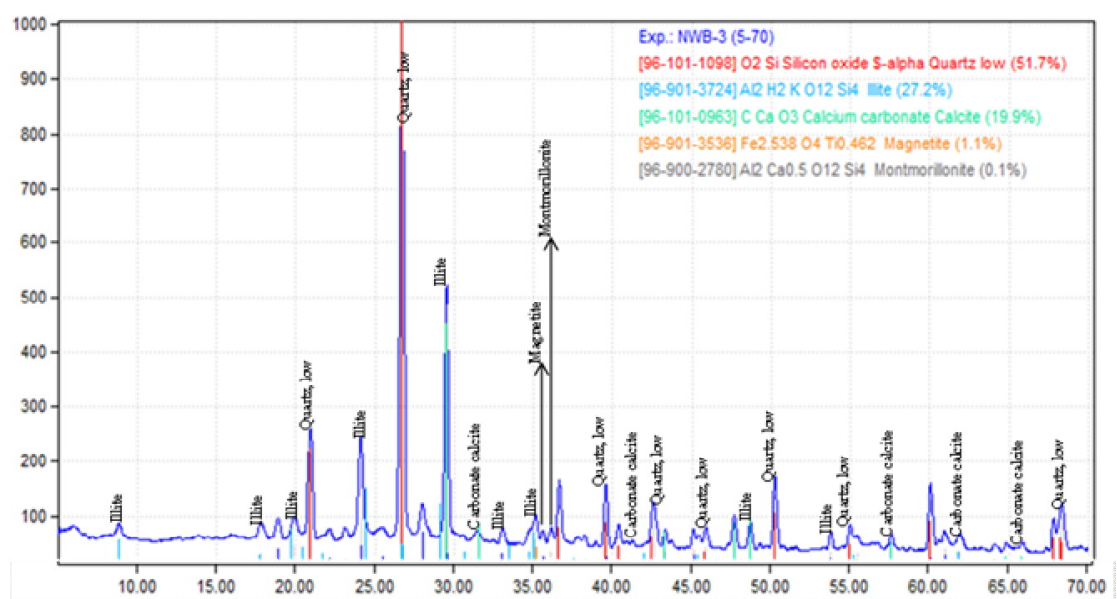

Gambar 8. Grafik XRD NWB 3

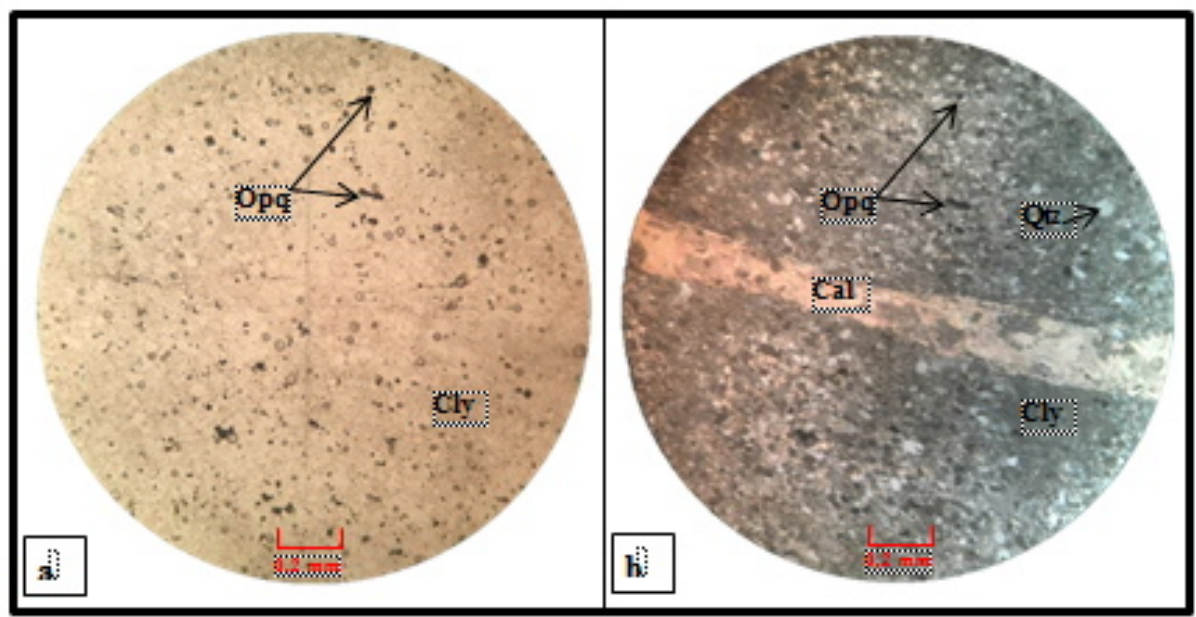

Gambar 9. Sayatan petrografi sampel batuan dari stasiun 03. Pada kenampakan nikol sejajar (a) dan nikol silang (b) yang tersusun atas mineral lempung (Cly), urat kalsit (Cal), mineral kuarsa (Qtz) dan mineral opak (Opq).

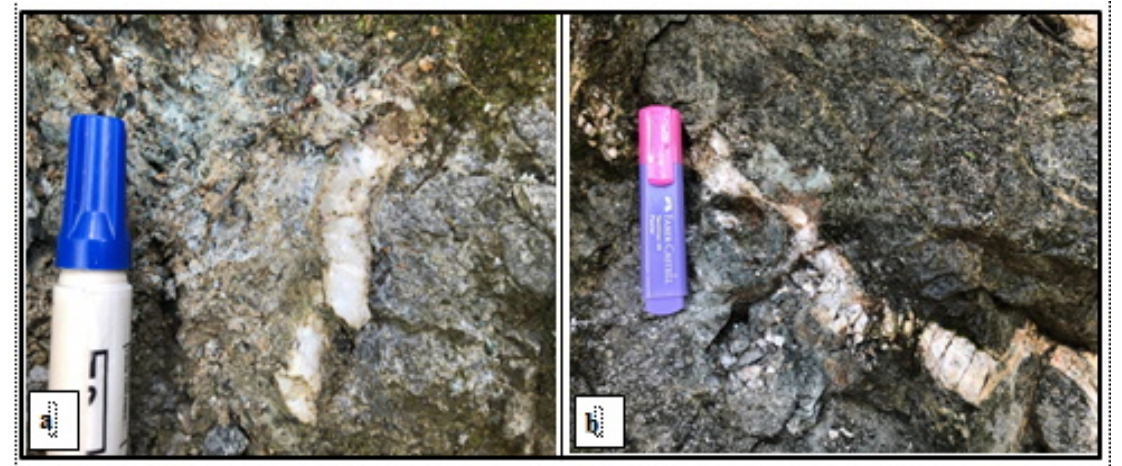

Gambar 10. Urat kalsit (a) dan urat kuarsa (b) dengan tekstur crustiform. 


\subsubsection{Jenis Mineral Bijih}

Berdasarkan analisis mikroskopis bijih (mineragrafi) pada empat sampel batuan, jenis mineral bijih yang dijumpai di daerah penelitian merupakan mineral-mineral golongan sulfida, antara lain: pirit $\left(\mathrm{FeS}_{2}\right)$, kalkopirit ( $\mathrm{CuFeS}_{2}$ ) dan kovelit (CuS).

Pirit pada kenampakan mikroskopis secara umum berwarna putih kekuningan dengan bentuk subhedral-anhedral. Mempunyai ukuran yang bervariasi yaitu 0.01-0.7 mm, tidak dijumpai adanya pleokroisme dan bersifat isotropik. Semua sampel batuan yang dianalisis dijumpai mineral pirit dalam bentuk disseminated mengisi rekahan-rekahan pada batuan (Gambar 11).

Kalkopirit pada kenampakan mikroskopis berwarna kuning dengan bentuk subhedralanhedral. M empunyai ukuran $<0.01 \mathrm{~mm}$, tidak dijumpai adanya pleokroisme dan bersifat isotropik. Kalkopirit dijumpai bersama pirit dalam bentuk disseminated mengisi rekahan pada sampel batuan NW B 1C (Gambar 11a).

Kovelit pada kenampakan mikroskopis berwarna biru tua dengan bentuk subhedralanhedral. Berukuran 0.01-0.02 mm, tidak dijumpai adanya pleokroisme dan bersifat anisotropik. Kovelit dijumpai bersama pirit pada sampel batuan NWB 1C dan NWB 6 (Gambar 1la dan 11b).

\subsubsection{Tekstur Mineral Bijih}

Berdasarkan analisis mineragrafi pada empat sayatan poles batuan, diketahui tekstur mineral bijih pada daerah penelitian terdiri dari tekstur pengisian (cavity filling), tekstur tumbuh bersama (intergrowth) dan tekstur penggantian (replacement).

Tekstur pengisian teramati pada mineral pirit yang hadir mengisi rekahan-rekahan pada batuan pada keempat sampel yang dianalisis mineragrafi (Gambar 11). Tekstur pengisian terjadi akibat adanya mineral lain yang mengisi pori atau rekahan pada mineral yang terbentuk sebel umnya (Craig \& V aughan, 1994).
Tekstur intergrowth (tumbuh bersama) hadir pada sebagian pirit dan kalkopirit (Gambar 11a). Hal ini menunjukkan suatu saat, pirit dan kalkopirit terbentuk bersamaan (Craig \& Vaughan, 1994; Ramdohr, 1969).

Tekstur penggantian (replacement) pada analisis mineragrafi ditunjukkan oleh mineral kovelit yang hadir menggantikan mineral kalkopirit pada sampel batuan NWB 1C (Gambar 11a) dan mineral kovelit yang hadir menggantikan sebagian dari tubuh pirit, yaitu pada sayatan poles sampel batuan NWB 6 (Gambar 11b).

\subsection{Paragenesa Mineral Bijih}

Mineral bijih yang hadir dari analisis mineragrafi adalah kalkopirit, pirit dan kovelit. Urutan pembentukan mineral bijih berdasarkan pengamatan tekstur yaitu diawali dengan pirit yang hadir mengisi rekahanrekahan pada batuan. Kehadiran pirit ini dijumpai pada keempat sampel yang dianalisis mineragrafi, baik sebagai mineral tunggal atau berasosiasi dengan mineral lain. Pada Gambar 11a terlihat adanya kehadiran kalkopirit (berwarna kuning) intergrowth dengan pirit. $\mathrm{Hal}$ ini menandakan kalkopirit hadir bersamaan dengan pirit. Pada Gambar 11a terlihat tekstur replacement kovelit terhadap kalkopirit, pada Gambar $\mathbf{1 1 b}$ terlihat replacement pirit oleh kovelit menunjukkan kehadiran kovelit setelah pirit dan kalkopirit.

Endapan hidrotermal di Daerah Wombo terjadi dalam dua tahap mineralisasi, pembentukan pirit yang mengisi rekahanrekahan pada batuan merupakan awal mineralisasi hipogen. Kemudian diikuti pembentukan mineralisasi pirit dan kalkopirit secara simultan. M ineral-mineral bijih tersebut terbentuk pada zona primer atau zona hipogen dibawah muka air tanah (Jensen \& Bateman, 1981), pada kisaran temperatur $200-300^{\circ} \mathrm{C}$ (Lawless dkk., 1998). 
Kemudian terjadi pengkayaan supergen yang ditandai dengan hadirnya kovelit yang mengganti (replacement) sebagian kalkopirit dan pirit. Penggantian kalkopirit dan pirit (sulfida primer) oleh kovelit (sulfida supergen) ini terjadi di bawah muka air tanah yaitu pada zona supergen (Jensen \& Bateman, 1981). Kisaran temperatur mineralisasi supergen, kurang dari $150^{\circ} \mathrm{C}$ (Lawless dkk., 1998).

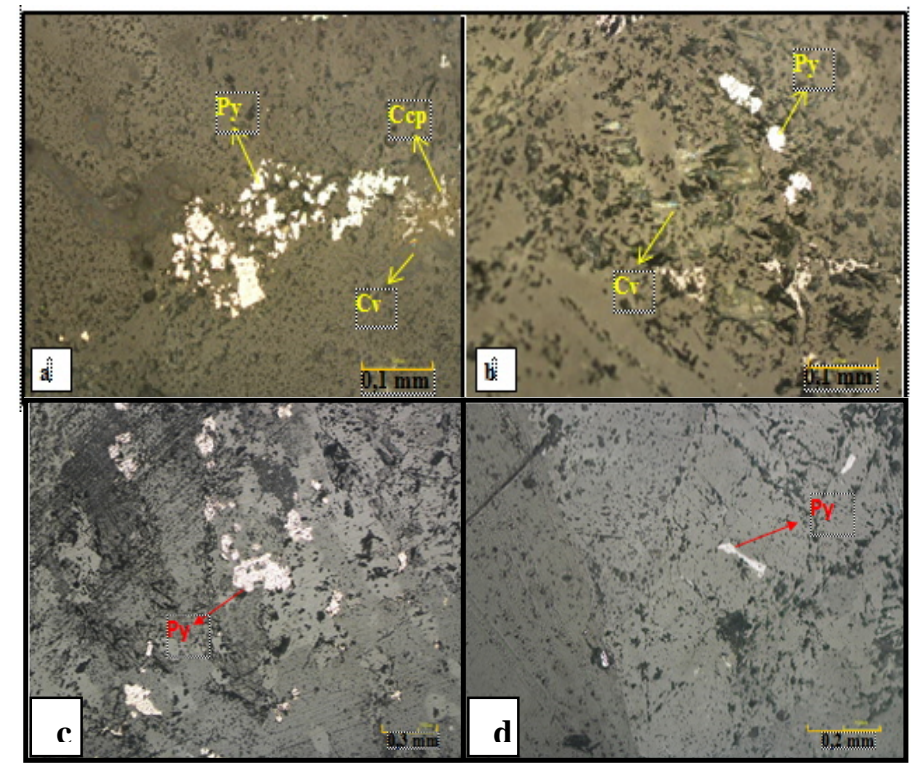

Gambar 11. (a) Sayatan poles sampel batuan NWB 1C menunjukkan tekstur intergrowth pirit dan kalkopirit juga tekstur replacement kalkopirit oleh kovelit. (b) Sayatan poles batuan NWB 6 menunjukkan mineral pirit hadir mengisi pori dan rekahan pada batuan yang memperlihatkan tekstur pengisian, juga terlihat tekstur replacement kovelit yang mengganti sebagian tubuh pirit. (c) Sayatan poles batuan NW B 4 menunjukkan tekstur pengisian oleh pirit. (d) Sayatan poles batuan NWB 7 menunjukkan tekstur pengisian oleh pirit.

Tahapan pembentukan mineral bijih sebagai paragenesa mineral bijih daerah penelitian dapat ditunjukkan pada Tabel $\mathbf{2}$.

Tabel 2. Paragenesa mineral bijih pada daerah penelitian.

\begin{tabular}{ccc}
\hline Mineral & \multicolumn{2}{c}{ Tahapan M ineralisasi } \\
\cline { 2 - 3 } Bijih & Hipogen & Supergen \\
\hline Pirit & & \\
Kalkopirit & \\
Kovelit & & \\
\hline
\end{tabular}

\section{KESIMPULAN}

Berdasarkan hasil penelitian dapat disimpulkan beberapa hal berikut. a. Alterasi hidrotermal di daerah penelitian terdiri dari dua tipe, yaitu: alterasi propilitik (klorit-zeolit-karbonat) dan alterasi argilik (ilit-kuarsa-karbonat).

b. Mineralisasi bijih di daerah penelitian ditandai dengan kehadiran mineral pirit $\left(\mathrm{FeS}_{2}\right)$, kalkopirit $\left(\mathrm{CuFeS}_{2}\right)$ dan kovelit (CuS). Urutan pembentukan mineral bijih berdasarkan pengamatan tekstur yaitu diawali dengan pirit yang hadir mengisi rekahan-rekahan pada batuan, kalkopirit intergrowth dengan pirit yang menandakan kalkopirit hadir bersamaan dengan pirit, replacement kovelit terhadap kalkopirit dan 
pirit menunjukkan kehadiran kovelit setelah pirit dan kalkopirit.

\section{UCAPAN TERIMA KASIH}

Penulis mengucapkan terima kasih kepada berbagai pihak terkait yang telah berkontribusi terhadap terlaksananya penelitian ini.

\section{DAFTAR PUSTAKA}

Bachri, S., \& Sidarto. (2013). Tektonik Sulawesi dalam: Geologi Sulawesi.

Corbett, G. J., \& Leach, T. M. (1998). Southwest Pacific Rim Gold-Copper Systems: Structure, Alteration, and Mineralization. Society of Economic Geologists. https://doi.org/10.5382/SP.06

Craig, J. R., \& Vaughan, D. J. (1994). Ore Microscopy and Ore Petrography. New York: John Wiley \& Sons, Inc.

Evans, A. M. (2009). An Introduction to Economic Geology and Its Environmental Impact. John Wiley \& Sons.

Hartusuwarno, S. (2005). Endapan Mineral. Laboratorium Petrologi dan Bahan Galian FTM UPN "V eteran" Y ogyakarta.

Idrus, A., Sufriadin, S., \& Nur, I. (2011). HYDROTHERMAL ORE MINERALIZATION IN SULAWESI: A VIEW POINT OF TECTONIC SETTING AND METALLOGENESIS.

Jensen, M. L., \& Bateman, A. M . (1981). Economic Mineral Deposits. John Wiley \& Sons, Inc.

Lawless, J. V., W hite, P. J., Bogie, I., Paterson, L. A., \& Cartwright, A. J. (1998). Hydrothermal Models., Mineral Deposits in The Arc Setting: Exploration Based on Mineralization Service. Kingston M orrison M ineral.

Leeuwen, v. T., \& Pieters, P. E. (2012). Mineral Deposits of Sulawesi. Geological Agency.

Magdalena, M. (2010). Studi Alterasi dan M ineralisasi Tembaga pada Area Tambang Batu Hijau. Institut Teknologi Bandung.

Marliani, M, dan Asrafil, A. (2021). (2021). Indication of Ore Mineralization in Bora Area, Sigi Regency, Central Sulawesi. In Journal of Physics: Conference Series Vol. 1763, No. 1, p. 012082.
Maulana, A. (2017). Endapan Mineral. Penerbit Ombak.

Maulana, A., Bröcker, M., \& Dan, W. (2020). Petrogenesis and geochronology of Cenozoic intrusions in the Poboya and Sassak gold and copper districts in Western Sulawesi, Indonesia: Implications for the mineralization processes and magma sources. Journal of Asian Earth Sciences, 193, 104303.

Pirajno, F. (2009). Hydrothermal Processes and Mineral Systems. Springer - Geological Survey of W estern Australia.

Ramdohr, P. (1969). The Ore Minerals and Their Intergrowths. Pergamon Press.

Ruppel, K. M. V., Dani, N., Remus, M. V. D., Ronchi, L. H., Gomes, M. E. B., \& Senhorinho, E. (2018). Temperature and Pressure in The Environment of Epithermal Alteration: A Case Study at Ibaré Lineament, Rio Grande do Sul, Brazil. Brazilian Journal of Geology, 48, 685702.

Syafrizal, Rivai, T. A., Yonezu, K., Kusumanto, D., Watanabe, K., \& Hede, A. N. H. (2017). Characteristics of a Low-Sulfidation Epithermal Deposit in the River Reef Zone and the Watuputih Hill, the Poboya Gold Prospect, Central Sulawesi, Indonesia: Host Rocks and Hydrothermal Alteration. M inerals, 7(7), 124.

Wajdi, M. F., Santoso, S. T. J., Kusumanto, D., \& Digdowirogo, S. (2011). M etamorphic Hosted Low Sulphidation Epithermal Gold System at Poboya, Central Sulawesi: A General Descriptive Review. In Proceedings of The Sulawesi M ineral Seminar, M anado, 201-210.

White, N. C., \& Hedenquist, J. W. (1995). Epithermal gold deposits. Styles, characteristics and exploration. SEG N ewsletter, 27, 1-13.

Winter, J. D. (2014). Principles of Igneous and Metamorphic Petrology (Vol. 2). Pearson Education.

Zar, A. T., Warmada, I. W., Setijadji, L. D., \& Watanabe, K. (2018). Alteration, vein textures and fluid inclusion petrography of metamorphic rock-hosted gold deposit at Onzonkanbani area, central M yanmar: Implication for its genesis. ASEAN Engineering Journal, 8(2), 48-63. 